\title{
Social attachment of the infant guinea pig to its parents in a two-choice situation
}

\author{
TERRY F. PETTIJOHN \\ Ohio State University, Marion, Ohio 43302
}

\begin{abstract}
Twenty-four domestic guinea pigs (12 of each gender) served as subjects in this study, which investigated attachment by testing amount of time (maximum $5 \mathrm{~min}$ ) the infants spent close to either the mother or the father in a two-choice situation during Weeks 2, 4,6 , and 8 after birth. Significantly more time was spent close to the mother during Weeks 2 and 4; reaction to the father appeared random. Time spent close to the mother declined across weeks, suggesting that maternal attachment weakens as the infant matures.
\end{abstract}

There have been several recent studies of attachment behavior in the infant guinea pig measured by the two-choice discrimination test. Gaston, Stout, and Tom (1969) and Sluckin (1968) found that when infant guinea pigs were briefly exposed to an object, they preferred it to other stimuli in a choice test. Harper (1970) reported that exposure of neonates to a vocalizing, furry, and moving model for 3 days was enough for the model to reinforce running behavior 5 days later (in a $\mathrm{T}$-maze with a model in one end and the other end empty).

Recently, social attachment also has been examined in older guinea pigs. Nagy and Misanin (1970) observed that at 135 days of age, guinea pigs spent more time in the end of a tilt cage containing an unfamiliar conspecific (as opposed to the empty end of the cage). Beauchamp and Hess (1971) reared neonates with a chicken, an adult female guinea pig, or their real mother and siblings, and then tested them weekly in a discrimination task between an unfamiliar chicken and guinea pig. For the first 3 weeks, the subjects preferred the species with which they were reared, while later, females showed no preference and males consistently chose guinea pigs.

All of the above studies tested subjects with a familiar stimulus and an unfamiliar one (or an empty chamber). Zajonc (1972) argued that in a two-choice discrimination task, the subject may approach the novel stimulus because of curiosity rather than attachment. Thus, caution should be taken to insure that the subject is familiar with both test stimuli. Porter, Fullerton, and Berryman (1973) tested infant guinea pigs in a two-choice situation for either their own mother or another lactating female (with whom they had also been housed). The infant guinea pigs showed

Reprint requests should be sent to Terry F. Pettijohn, Department of Psychology, The Ohio State University, Marion, Ohio 43302. The author wishes to thank J. Panksepp, C. Mynatt, S. Vessey, and especially J. P. Scott for their helpful comments on the manuscript. no preference; however, the mothers preferred their own litter to another of the same age. Fullerton, Berryman, and Porter (1974) found that infants tended more often to nurse and remain in proximity to their biological mother as opposed to another lactating female with which they were also housed. However, when the infants were isolated for a short period of time and returned, their behavior tended to be indiscriminant, while the adult females again preferred their own young to that of the other mother.

The reviewed research suggests that although the infant guinea pig may form early attachments, the attachment is not strong and does not last long. However, due to confounding (using novel stimulus in testing) and limited test time (first month in some studies), attachment was not precisely measured by the two-choice situation. In the present study, infant guinea pigs were tested for amount of time spent close to two familiar social objects (mother and father) during the first 2 months of life. This allowed developmental aspects to be evaluated and eliminated the confounding effects of presenting an unfamiliar stimulus for testing.

\section{METHODS}

\begin{abstract}
Subjects
Twelve male and 12 female domestic guinea pigs (Cavia porcellus) from eight litters served as subjects for this study. All animals were born and reared in the guinea pig colony room. Each litter and its parents were housed in plywood boxes $(60 \times 90 \times$ $30 \mathrm{~cm}$ ) painted with nonlead white on the inside. The floor of the box was covered with hardwood chips, and Wayne Guinea Pig Chow and water were continuously available. The colony room was maintained at $23^{\circ} \mathrm{C}$ and was on a 12 -h light: 12 -h dark cycle (lights on at 7 a.m.).
\end{abstract}

\section{Apparatus}

The subjects were tested in a clean, unfamiliar box of the same dimensions as the home box. It contained bedding, but no food or water. The test box was modified as illustrated in Figure 1 by the placement of a $30 \times 60 \mathrm{~cm}$ piece of $2-\mathrm{cm}$ white plywood midway between the two sides of one end of the box. 


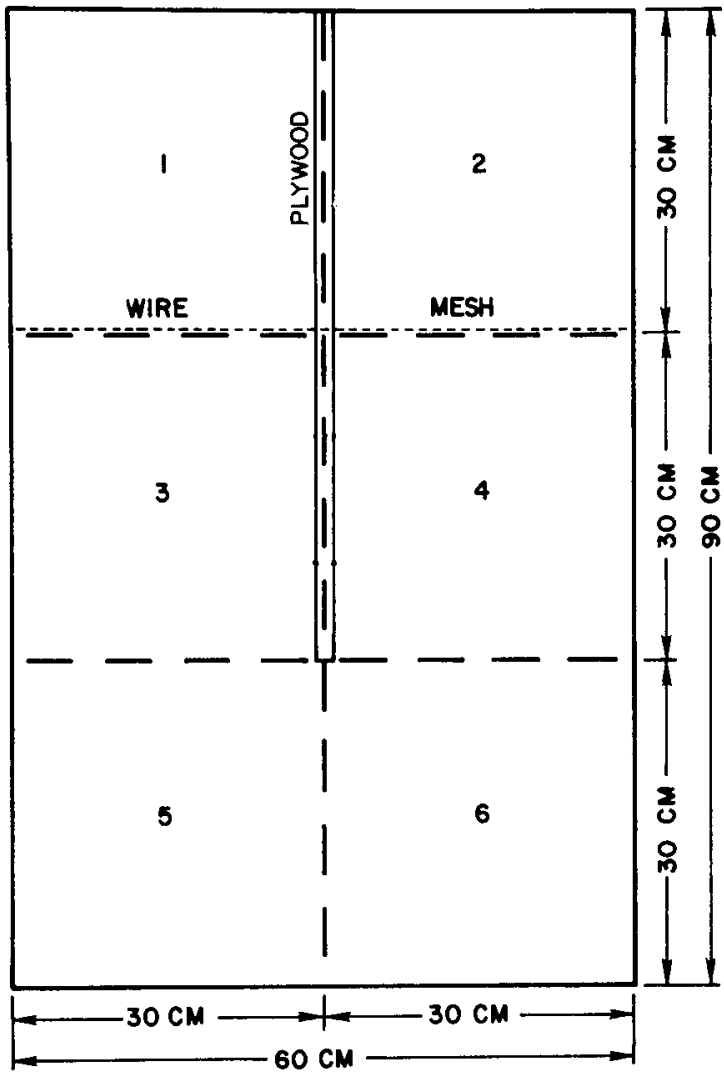

Figare 1. Modifications of home box to test attachment in a two-choice situation.

The plywood extended two-thirds of the length of the box, ending so that a $30 \times 60 \mathrm{~cm}$ section was not included in the bisection. Wire mesh was placed so as to create two $30 \times 30 \mathrm{~cm}$ compartments at the bisected end of the box. These modifications made six $30 \times 30 \mathrm{~cm}$ sections in the test box, which could be sequentially numbered as follows: 1 and 2 in the compartments produced by wire mesh and plywood, 3 and 4 in the bisected center of the box, and 5 and 6 in the open end of the box.

\section{Procedure}

Each subject was tested on Wednesday morning of Weeks 2, 4,6 , and 8 after birth. The subject's mother and father were placed separately in one of the bisected end compartments (Sections 1 and 2), the location of each being determined by change. After $1 \mathrm{~min}$ had elapsed, the young subject was placed at the opposite open end of the box (Sections 5 and 6), facing the end of the dividing piece of plywood.

Observations were recorded for $5 \mathrm{~min}$. The main dependent measure was the number of seconds spent in the section closest to each parent (Sections 3 and 4). Other behaviors, including distress vocalizations, freezing, and grooming were recorded, using a behavior code sheet.

\section{RESULTS}

The infant guinea pigs appeared noticeably disturbed when first placed in the test box. They vocalized while visually exploring their new surroundings. After a short while, they usually approached one of the parents and stopped vocalizing. Some would remain near the first parent they had approached, but more often they remained active and moved about the box, approaching both parents several times.

Figure 2 shows the amount of time the infant guinea pigs spent in the section closest to each parent. Since the subjects could move about in four sections (Sections 3, 4, 5, and 6), it was hypothesized that if responding was random, the animals should have spent abut $25 \%$ of the time $(75 \mathrm{sec})$ in each section. As shown in Figure 2, the subjects did not differ from random behavior with regard to the father, but did spend more time close to the mother in Weeks 2 and 4 than would be predicted if they had responded randomly. The numbers of subjects that spent more time close to the mother were $19,21,15$, and 11 for Weeks 2, 4, 6, and 8, respectively.

A t test for nonindependent measures was applied to the time (seconds) each subject spent in the section next to the mother vs. the time sent in the section next to the father. For Week 2, the subjects spent significantly more time close to the mother $[t(23)=2.66, p<.025]$. For Week 4 , the infant guinea pigs also chose to be near their mothers significantly more than near their fathers $[\mathrm{t}(23)=4.21$, $\mathrm{p}<.005]$. The scores for Weeks 6 and 8 were not significantly different, and, as shown in Figure 2, the time spent with each parent was similar and not too deviant from the predicted $75 \mathrm{sec}$.

Although the time spent next to the father remained fairly constant across time, the total time spent next to any parent declined over weeks. The mean combined time spent in either section closest to a parent was $230,234,206$, and $166 \mathrm{sec}$ for Weeks $2,4,6$, and 8 , respectively. A t test for nonindependent measures was carried out for each week on the time each subject spent in the two sections closer to the parents

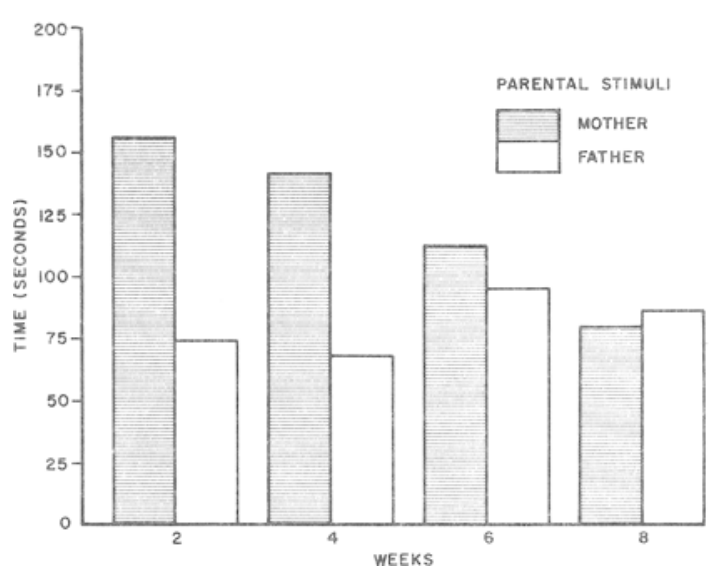

Figure 2. Amount of time infants spent in the section next to each parent. 
(Sections 3 and 4) vs. the two sections farther away (Sections 5 and 6). The scores for Weeks 2, 4, and 6 were all significant at the $p<.005$ level, while the scores for Week 8 were nonsignificant. Thus, during the first three test periods, the subjects spent more time close to a parent, while for the last test period, the subjects behaved randomly. These results can be accounted for by the fact that the time spent next to the mother declined across time.

Distress vocalizations of the subjects tended to parallel the time spent with the mother. A subject typically vocalized only during the 1 st minute or until it began to explore and find a parent. The mean vocalization rates for the subjects while being tested were $42.8,25.8,12.0$, and 1.0 for Weeks $2,4,6$, and 8 respectively. These rates were significantly different as evaluated by the Friedman two-way analysis of variance by ranks $\left[\chi_{\mathrm{r}}^{2}(3)=33.1, \mathrm{p}<.001\right]$. The low vocalization rates can be accounted for by the technique of testing in a social situation.

\section{DISCUSSION}

The present experiment used both parents (familiar social stimuli), and therefore time spent close to the mother could not have been due to attraction to or fear of novel test stimuli. It can be reasonably concluded that the subjects spent more time close to their mother than to their father in this two-choice social stiuation during Weeks 2 and 4 because of their attachment to her.

The subjects were not able to have any physical contact with their parents except through the wire mesh, and therefore were not able to nurse during the test sessions. However, contact through available sensory modalities (auditory, visual, and olfactory) was sufficient to motivate the subjects to maintain proximity to the mother during tests in Weeks 2 and 4. The first two test periods correspond to the time the infants were being nursed and most cared for by their mothers, as found in observational data collected by the author (Pettijohn, 1978). These data, and the author's finding (Pettijohn, 1977) that mothers (but not fathers) responded to a recording of infant distress vocalization only during the 1st week of life, strongly suggest that the subject's behavior was influenced by the mother. Carter and Marr (1970) reported that olfactory imprinting was possible in infant guinea pigs, and since the subjects were usually in contact with their mother in the home condition, they may have been responding to the mother's smell. The infants might also have been able to discriminate on the basis of coat markings. Or the mothers might have attracted the subjects in the early sessions because they were more actively trying to reach their offspring.
The present results suggest that the infant guinea pig might lose its attachment for a parent as the infant matures. However, another interpretation is possible, based on the work of Porter, Berryman, and Fullerton (1973), who found that infant guinea pigs showed a higher exploration rate when the mother was present although confined. In the current research, the subjects might have felt secure even in the farthest corner of the box. Perhaps the attachment is as strong in later weeks, but the need to actually be in close proximity is not as great. Older guinea pigs might be able to communciate attachment through audition, vision, and olfaction, without actually being in close proximity to the attachment stimulus. It is also possible that because of the repeated testing design employed in the current study, familarity to the test apparatus might have contributed to the decline of attachment behavior over time, Although this possibility was not tested in the current study, the author has shown in a study on distress vocalization (Pettijohn, 1979) that the infant guinea pig does not readily habituate to the testing apparatus.

The present results agree, in general, with the findings of previous research, that the infant guinea pig can develop an attachment early in life, which appears to weaken as the animal matures. They also extend the idea that the mother is the prime attachment object. The present research shows the feasibility of measuring attachment when both test stimuli in a two-choice situation are familiar to the subject. This technique can be useful to researchers interested in the precise factors (auditory, visual, olfactory) which determine the attachment process in the guinea pig.

\section{REFERENCES}

Beauchamp, G. K., \& Hess, E. H. The effects of crossspecies rearing on the social and sexual preferences of guinea pigs. Zeitschrift für Tierpsychologie, 1971, 28, 69-76.

CarTer, C. S., \& MARR, J. N. Olfactory imprinting and age variables in the guinea pig, Cavia porcellus. Animal Behaviour, 1970, 18, 238-244.

Fullerton, C., Berryman, J., \& Porter, R. On the nature of mother-infant interactions in the guinea pig (Cavia porcellus). Behaviour, 1974, 48, 145-156.

Gaston, M. G., Stout, G. R., \& Tom, R. Imprinting in guinea pigs. Psychonomic Science, 1969, 16, 53-54.

HARPER, L. V. Role of contact and sound in eliciting filial responses and development of social attachment in domestic guinea pigs. Journal of Comparative and Physiological Psychology, 1970, 73, 427-435.

NAGY, Z. M., \& Misanin, J. R. Social preference in the guinea pig as a function of social rearing conditions and age at separation from the mother. Psychonomic Science, 1970, 19, 309-311.

Pettijohn, T. F. Reaction of parents to recorded infant guinea pig distress vocalization. Behavioral Biology, 1977, 21, 438-442. 
Petтujohn, T. F. Development of social behavior in young guinea pigs (Cavia porcellus). Journal of General Psychology, $1978,99,81-86$.

Pettijohn, T. F. Attachment and separation distress in the infant guinea pig. Developmental Psychobiology, 1979, 12, 73-81.

Porter, R., Berryman, J., \& Fullerton, G. Exploration and attachment behavior in infant guinea pigs. Behaviour, 1973, 45, 312-322.
Porter, R., Fullerton, C., \& Berryman, J. Guinea pig maternal-young attachment behavior. Zeitschrift für Tierpsychologie, 1973, 32, 489-495.

SLUCKIN, W. Imprinting in guinea pigs. Nature, 1968, 220, 1148.

Zajonc, R. B. Animal social behavior. Morristown, N.J: General Learning Press, 1972.

(Received for publication February 4, 1977; revision accepted September 30, 1978.) 